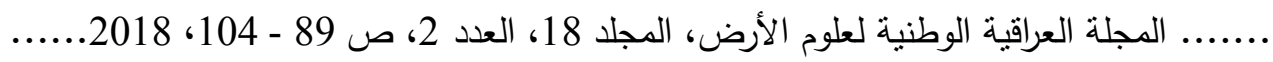

استخدام طريقة المسح الزلزالي الانكساري التصويري وتقتية التحليل متعدد القتوات للموجات السطحية في عملية التقييم الجيوتكنيكي لموقع شقق الأمل في كركوك، شمالي العرلق الاكيل

\author{
محمود عبدالله المفرجي \\ بشار عزيز الجريسي \\ علي زهير النعيمي \\ قسم الجبيولوجيا التطبيقية

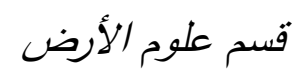 \\ قسم علوم الأرض تصني \\ كلية العلوم \\ كلبة العلوم \\ كلية العلوم \\ جامعة كركوك \\ جامعة الموصل \\ جامعة الموصل \\ (تاريخ الاستلام 2018/6/6 تاريخ القبول 2018/8/19 )
}

\section{الملخص}

تضمن البحث الحالي اجراء مسح زلزالي انكساري باستخدام طريقة المسح الزلزالي الانكساري

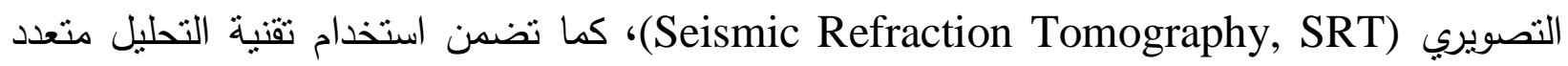
القنوات للموجات السطحية (Multi-channel Analysis of Surface Waves, MASW) لموقع شقق الأمل في محافظة كركوك شمالي العراق من أجل تحديد سمك الطبقات تحت السطحية وعمقها وسرعتها،

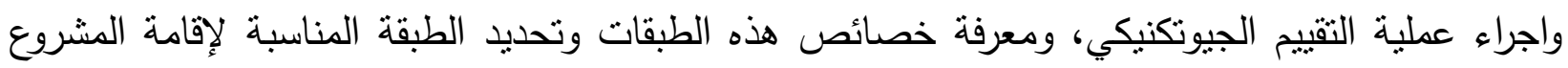

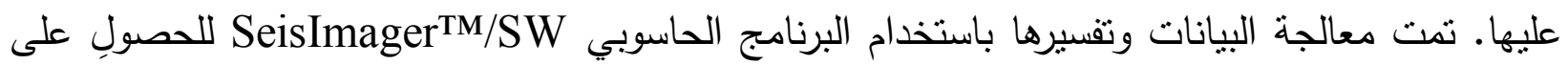

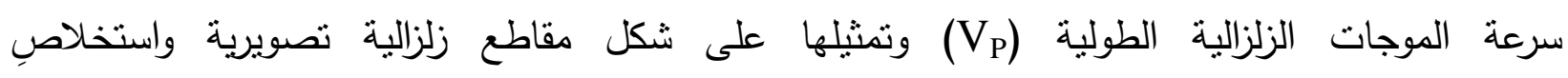

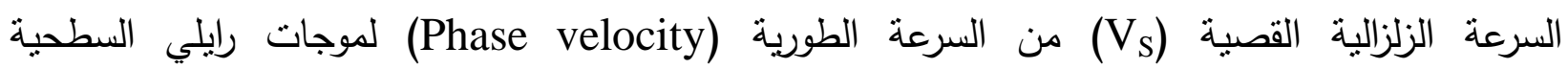
(Rayleigh surface waves) ثنائية البعد تمنل السرعة الطولية (V) مع العمق لخطوط المسح كما تم الحصول على ثلاثة مقاطع أحادية

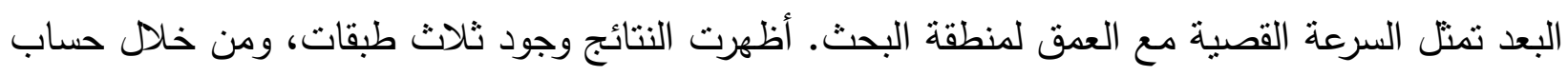

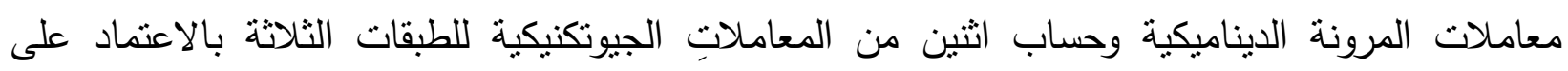

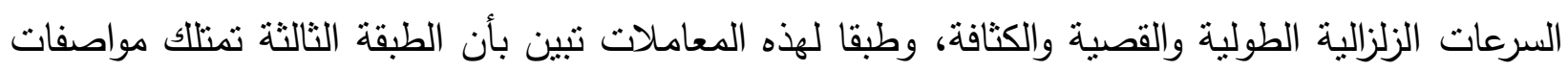
جيوتكنيكية أفضل من الطبقات التي تعلوها، وهي مناسبة لإقامة المشروع الهندسي عليها. الكلمات الدالة: الطريقة الانكسارية، المسح التصويري، تقنية التحليل متعدد القنوات، التقييم الجيوتكنيكي. 


\title{
The Use of the Seismic Refraction Tomography Survey Method and the Multi-Channel Analysis Technique of Surface Waves in the Geotechnical Assessment of the Al-Amal Apartments Site in Kirkuk, Northern Iraq
}

\author{
Ali Z. Al-Nuaiemy \\ Department of Geology \\ Geology of Science \\ University of Mosul
}

\author{
Bashar A. Al-Juraisy \\ Department of Geology \\ College of Science \\ University of Mosul
}

\author{
Mahmood A. Al-Mafraji \\ Department of Applied \\ College of Science \\ University of Kirkuk
}

\begin{abstract}
The current study conducted a seismic refraction survey using seismic refraction tomography (SRT), and the use of the multi-channel analysis technique of surface waves (MASW) at the site of Al-Amal apartments in Kirkuk Governorate ( northern Iraq) in order to determine the thickness, depth and velocity of the sub-surface layers. Moreover, a geotechnical assessment is measured in addition to determining the characteristics of these layers and specifying the appropriate layer for establishing the project.The data are processed and interpreted by using SeisImager ${ }^{\mathrm{TM}} / \mathrm{SW}$ software to obtain the velocity of longitudinal waves $\left(V_{P}\right)$ represented in the form of a seismic tomography section. The velocity of shear waves $\left(\mathrm{V}_{\mathrm{S}}\right)$ is extracted from the phase velocity of Rayleigh surface waves using MASW method. The 2D seismic tomography sections represent longitudinal velocity $\left(\mathrm{V}_{\mathrm{P}}\right)$ and the depth of the survey lines. It also has been got three onedimensional sections representing shear waves $\left(V_{S}\right)$ with the depth. The results show the presence of three layers, and through dynamic flexibility parameters are calculated, and two of geotechnical parameters are applied for the three layers based on the seismic velocity of longitudinal, shear and density. According to these geotechnical parameters, the third layer has better geotechnical specifications than the layers above it, which is suitable for the engineering project.
\end{abstract}

Keywords: Refraction Method, Tomography Survey, Multi-Channel Analysis Technique (MASW), Geotechnical Assessment.

\section{المقدمة}

Seismic Refraction تعد طريقة التصوير المقطعي او ما يسمى (الانكسار الزلزالي التصويري واحدة من الطرائق الجيوفيزيائية الحديثة التي تستخدم لتفسير اليبانات الزلزالية (Tomography, SRT)

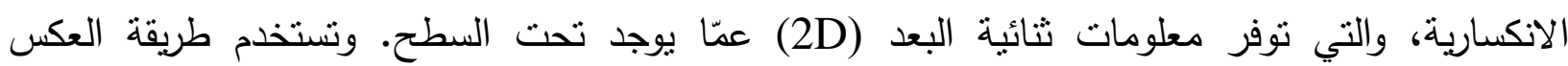
لتحديد سرعة الطبقات ورسم مقاطع لها (Inversion) هذه الطريقة على التقاط أزمنة الوصول حيث تقوم البرامج الخاصة بهذه الطريقة باختيار أفضل نطابق 
للسرعة عن طريق مبدأ التكرار (Iteration) حيث يتم أولا انثاء موديل ابتدائي (Initial Model) من قبل المفسر ويتم تعديل الموديل الابتدائي لنقليل الفرق بين زمن وصول الموجات المحسوب (Calculated) وبين مئن اليانات الفعلية (الزمن الملحوظ) (Observed) لنحصل على موديل ثنائي البعد حيث يظهر التذربن

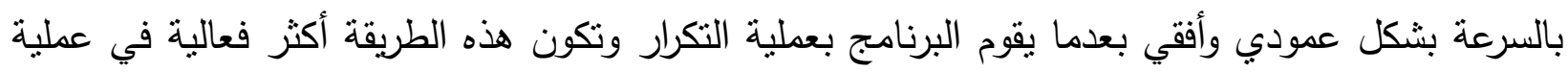
التحريات الموقعية، ومعرفة خصائص الموقع بالمقارنة مع طريقة المسح الزلزالي الانكساري التقليدية .(Azwin et al., 2013)

أجريت في العراق العديد من الدراسات التي استخدمت طريقة المسح الزلزالي الانكساري لأغراض

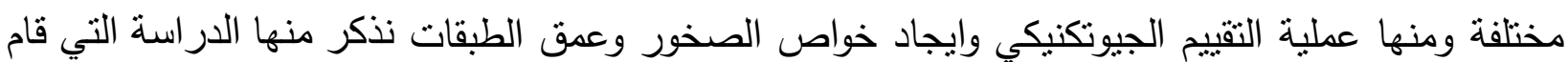
بها (2014,. Khorshid et al) حيث استخدم الطريقة الزلزالية الانكسارية في التقييم الجيوتكنيكي لتربة ونية

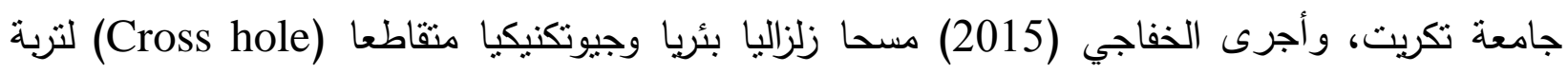
موقع فندق الخيام في محافظة كربلاء لمعرفة مناطق الضعف وان وأعماقها. ان تقنية التحليل متعدد القنوات للموجات السطحية (MASW) وهي طريقة استكثاف زلزالية لنقدير

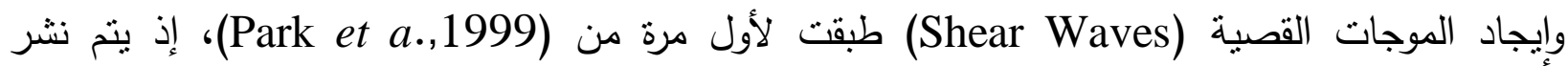

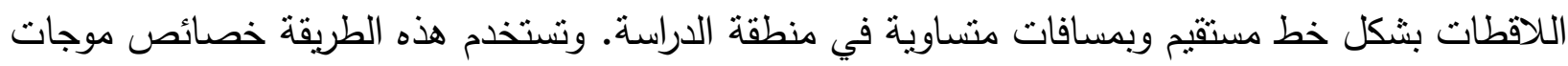
رايلي (Rayleigh waves) للحصول على سرعة الموجات القصية، وتستخدم بشكل كبير في التطبيقات ذات العمق الضحل المتعلقة بالأعمال البيئية والهندية والجيوتكنيكية. تقسم طريقة (MASW) الى نوعية ونئين

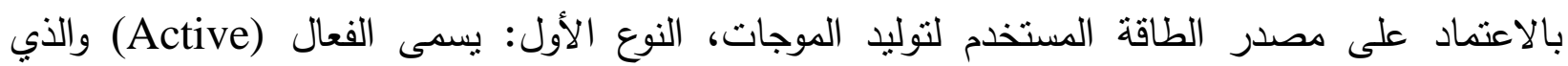

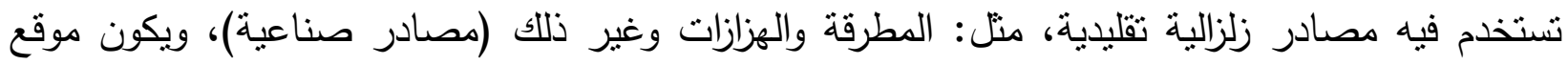
المصدر معلوما، والنوع الثاني: يسمى السلبي (Passive) ويعتمد على المصادر الطبيعية، مثل: النشاط

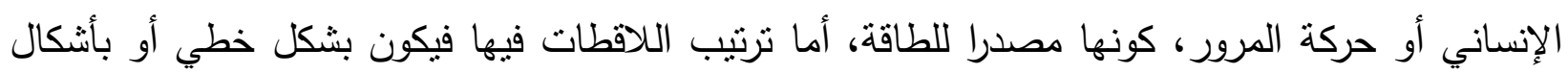
هندسية مختلفة (Park et al., 2007) اذ يمثل المصدر (الضوضاء المحيطة) والتي تنتشر في مختلف

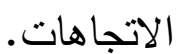

أجريت في العراق دراسات استخدمت فيها تقنية (MASW)، إذ قام (Shakir,2012) بإجراء دراسة

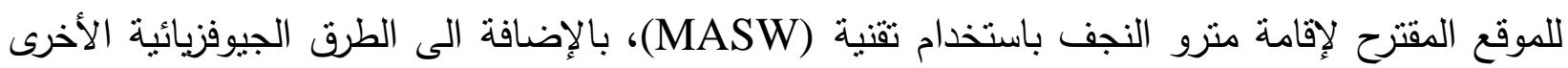

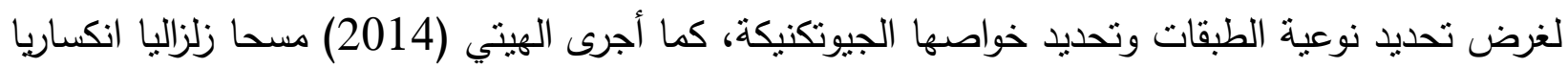
لموقع المستشفى التعليمي في جامعة الموصل، واستخدم تقنية (MASW) لتحديد سمك الطبقات وحساب بعض المعاملات الهندسية. 


\section{موقع منطقة الدراسة}

تقع منطقة الدراسة ( الثكل 1) بين خطي ("46 '24 35٪) شمالاً و ("15 22' 44) شرقاً في الجانب الثرقي من مدينة كركوك بالقرب من نهر الخاصة. تمنل منطقة الدراسة موقعا مقترحا لإنشاء عمارة

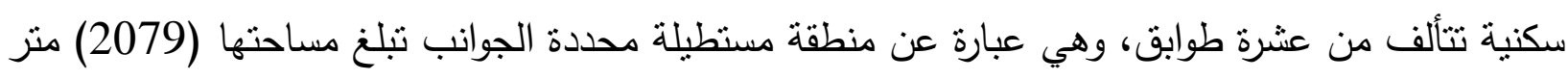

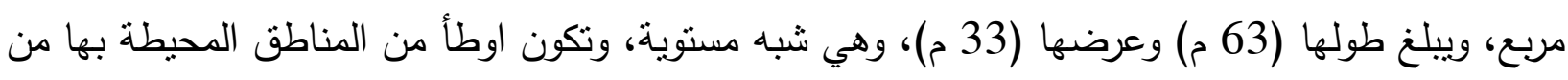

\section{جيولوجية منطقة الاراسة}

ناحية الارتفاع.

تقع محافظة كركوك ضمن الرصيف القاري غير المستقر (unstable shelf)، وقنم (Sissakian.,1992) محافظة كركوك الى قسمين: المنطقة الاولى تتألف من اراضي شبه منبسطة ومن هضاب متموجة وبعض التلال وتقع منطقة الدراسة ضمن هذه المنطقة، تتألف المنطقة الثانية من منطقة

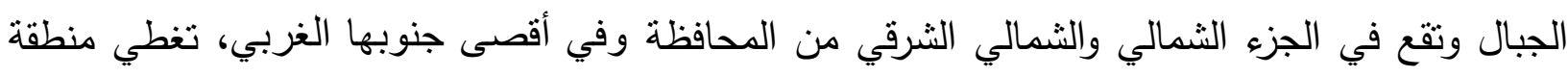

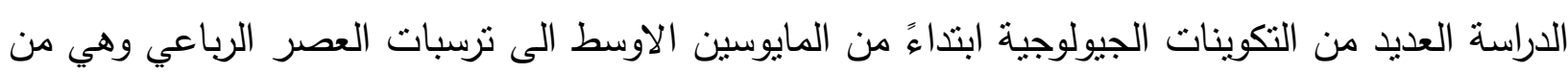

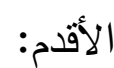

• تكوين فتحةة: ويعود عمر هذا التكوين الى المايوسين الاوسط، ويتكون من تعاقبات صخور الانهدرايت والجبس والملح وتتداخل مع صخور الحجر الجيري والمارل (Bellen et al.,1959) •

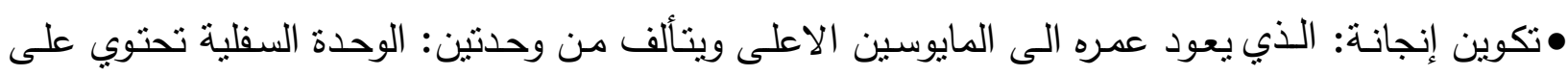

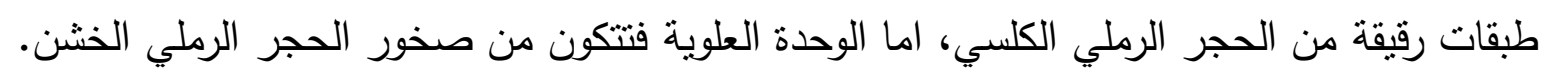

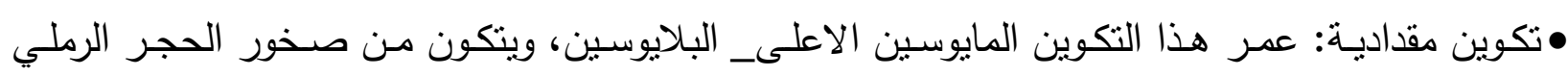

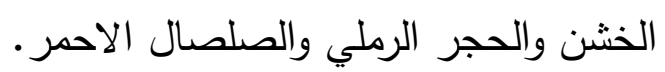
• تكوين باي حسن: يعود عمره الى البلايوسين، ويتكون من المدملكات، ويمكن تحديده بظهور اول طبقة من

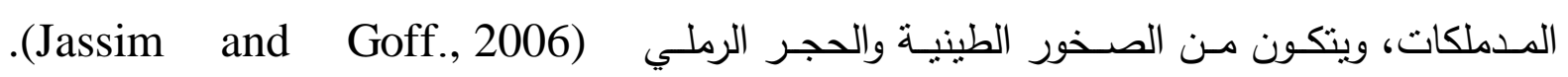

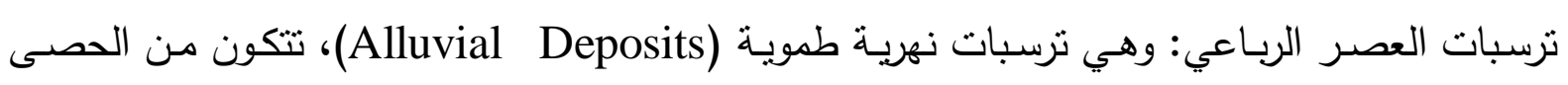
والرمل والغرين والطين. 


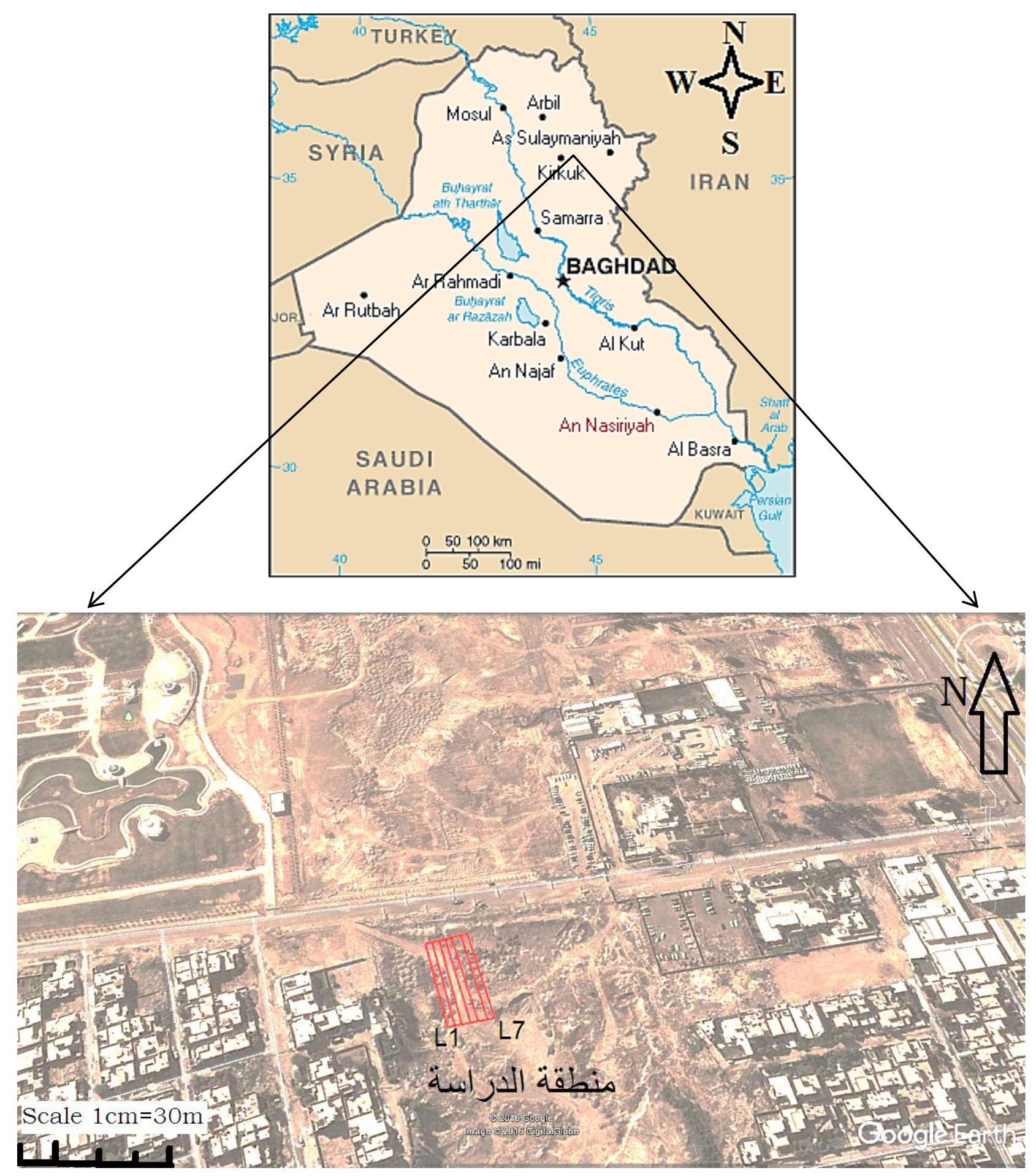

الثكل 1: خارطة ومرئية فضائية تبين موقع منطقة الدراسة موضحا عليها خطوط

$$
\text { المسح الزلزالي الانكساري. }
$$




\section{علي زهير النعيمي واخرون \\ جمع البيانات}

أجري المسح الزلزالي الانكساري على امتداد سبعة خطوط منوازية باتجاه (شمال-جنوب) وبطول

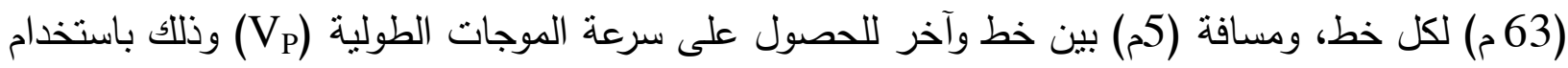

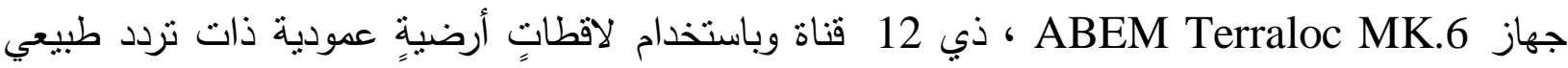
(10 Hz) بطول (33م) لكل مسار وبتداخل (Overlap) مقداره (18م) بين مسار وآخر ، وقد كانت المسافة بين لاقطة وأخرى (3م). كما نم اجراء المسح على مسار عمودي على الخطوط السابقة (أمامي ومعكوس) باتجاه

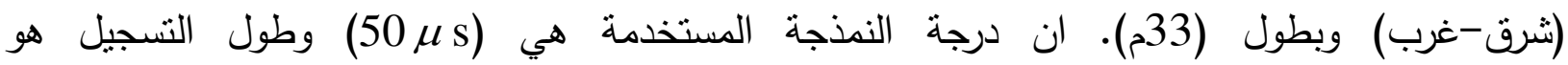
.(819.2 msec)

استخدام تقنية (MASW) تمت عن طريق اجراء مسح زلزالي انكساري (أمامي ومعكوس ووسطي)

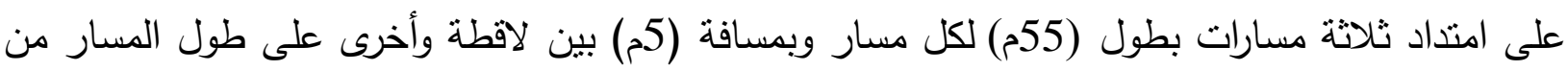

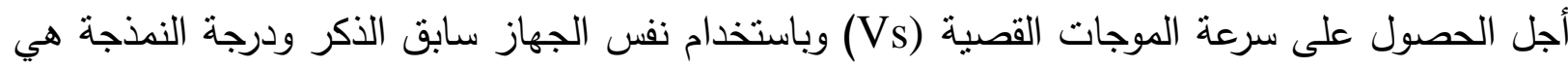

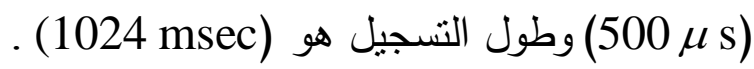

\section{معالجة وتفسير البيانات بطريقة التصوير المقطعي}

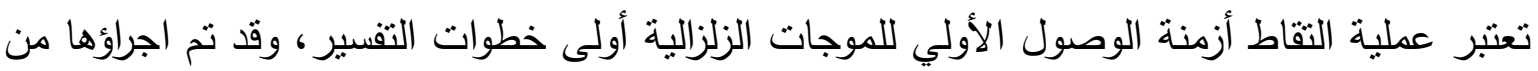
خلال برنامج Pickwin، فبعد ازالة الضوضاء يقوم البرنامج بعملية الالتقاط للأزمنة أوتوماتيكيا،

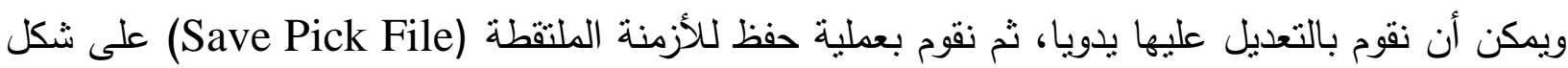
ملف ذي صيغة (vs)، هذا الملف ينم فتحه من خلال برنامج التفسير وهو (نlotrefa Analysis)

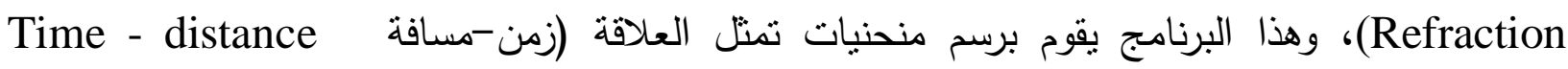
curve والتي استخدمت لوضع موديل السرعة Velocity model، و الموديل الطبقي Layered model لمنطقة الدراسة. وتعمل هذه البرامج على تمثيل البيانات بشكل مقاطع عرضية (Cross-Section) تمنل ما يوجد تحت السطح عن طريق عكس منحني (مسافة_زمن).

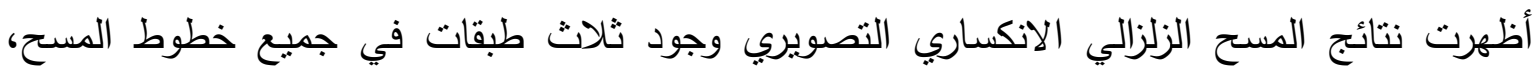

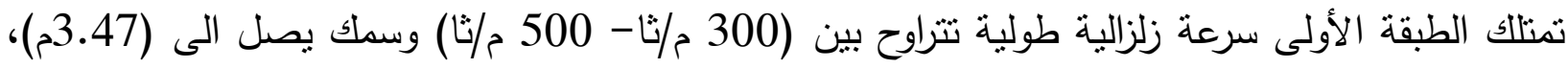

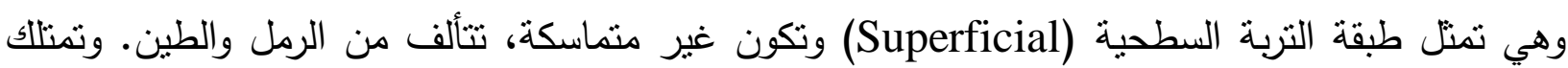

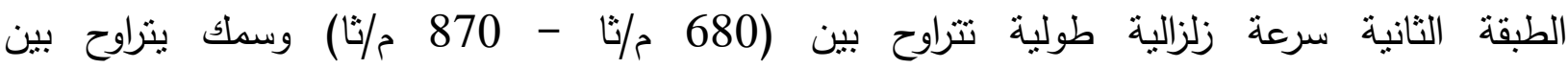

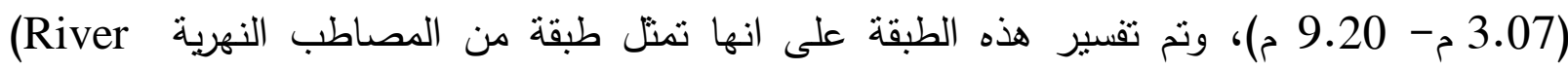
والني تتألف من رواسب نهرية من المواد الطينية والغرينية والحصى والطين والرمل، 
وتعود أعمارها الى عصر البلاستوسين، ويمكن مشاهدتها بالقرب من نهر الخاصة وفي مقالع الحصى والرمل، أو بعد تجوية الجزء العلوي من التربة السطحية ، أما الطبقة الثالثة فتمتلك سرعة زلزالية طولية تتراوح بين (1250 م/ثا- 1800 م/ثا) وعمقها يتراوح بين ( 4.08م- 9.74 م)، تم تفسير هذه الطبقة على أنها تمنل الجزء العلوي من تكوين باي حسن الذي يتكون من المدملكات والصخور الطينية والرملية، ويختلف عن المصاطب النهربة باحتوائه على نسبة من الكاربونات تقدر بـ 30\% ، ويعود عمره الى البلايوسين ، وهذا التفسير يتوافق مع المعلومات التي تم الحصول عليها من خلال المشاهدات الحقلية للمكاشف الصخرية القربية ومع الآبار المحفورة بالقرب من منطقة الدراسة، والأشكال (2، 3، 4) تمثل نموذجاً لنتائج المسح

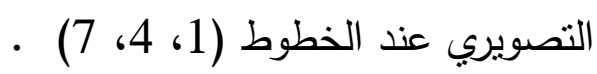

a: Seismic Refraction

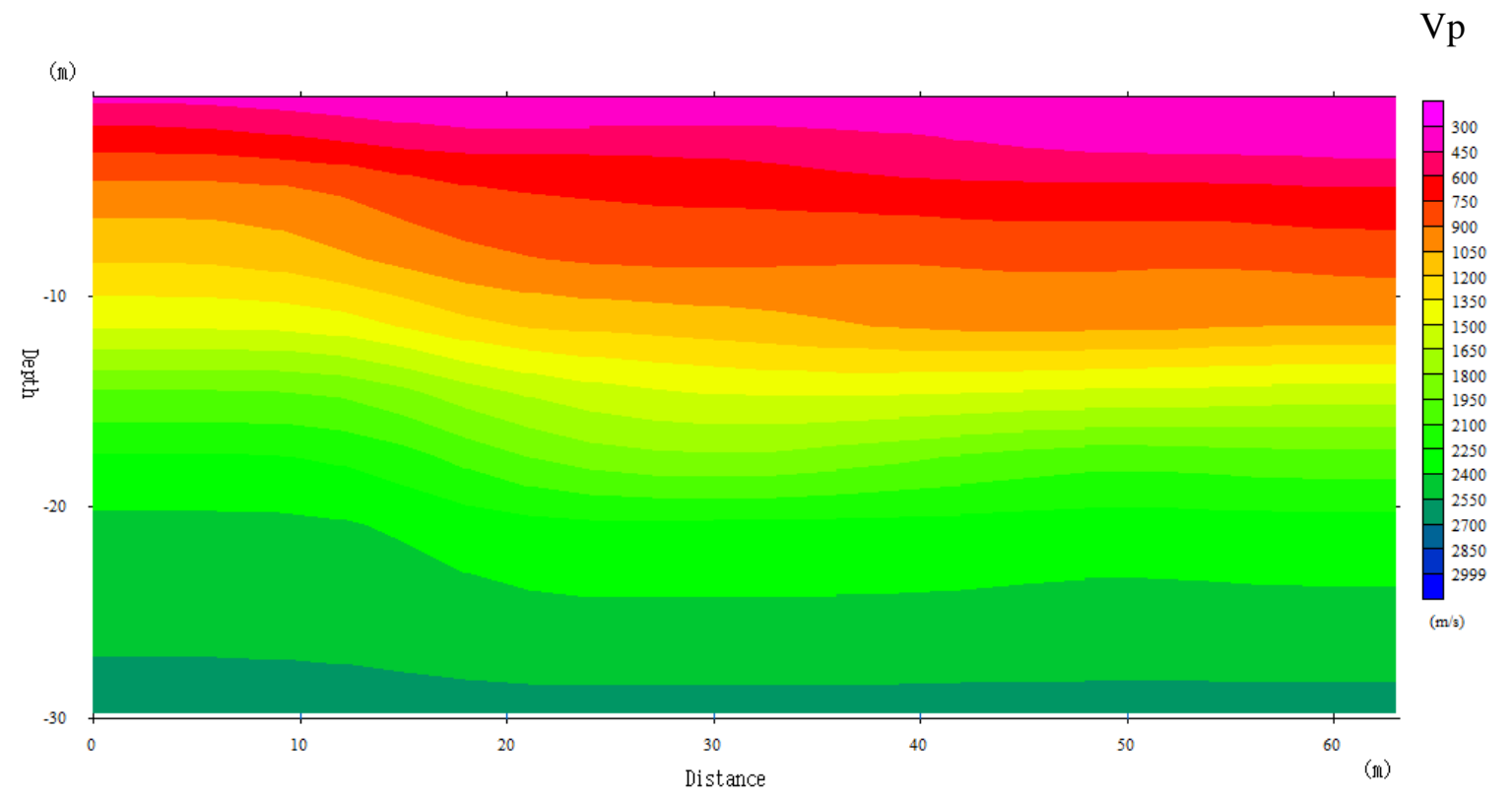

b: Layered model

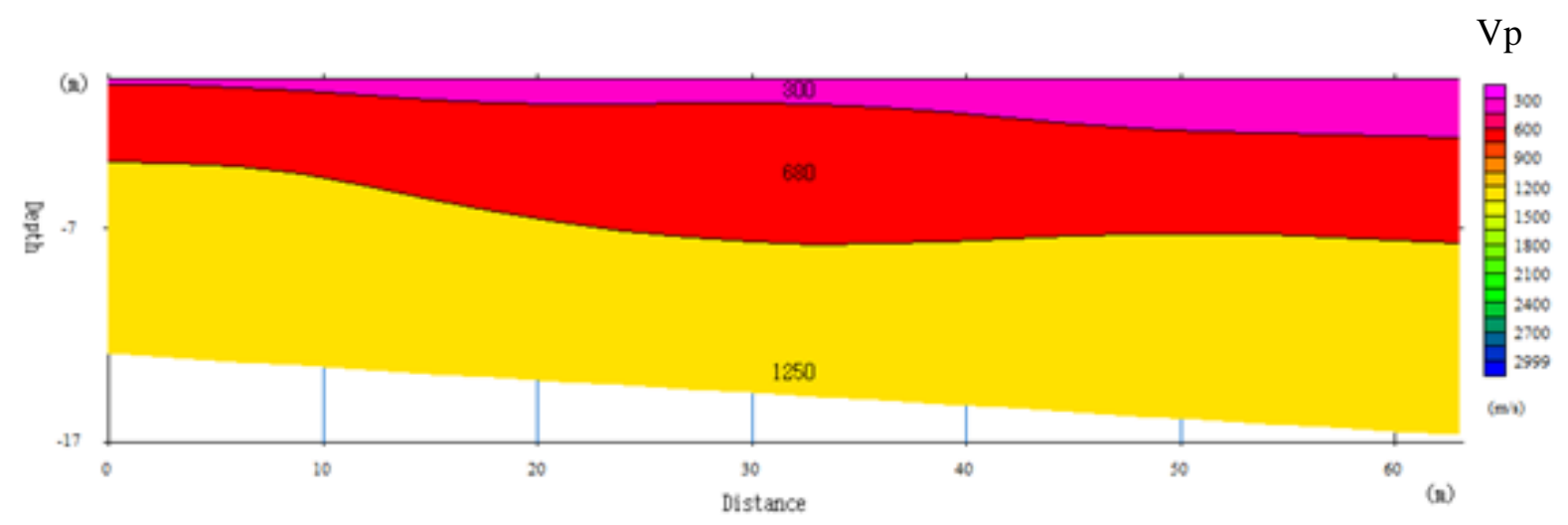

الثنكل 2: يمثل a مقطع زلزالي تصويري للخط الأول.

b: مقطع زلزالي طبقي للخط الأول. 
a: Seismic Refraction

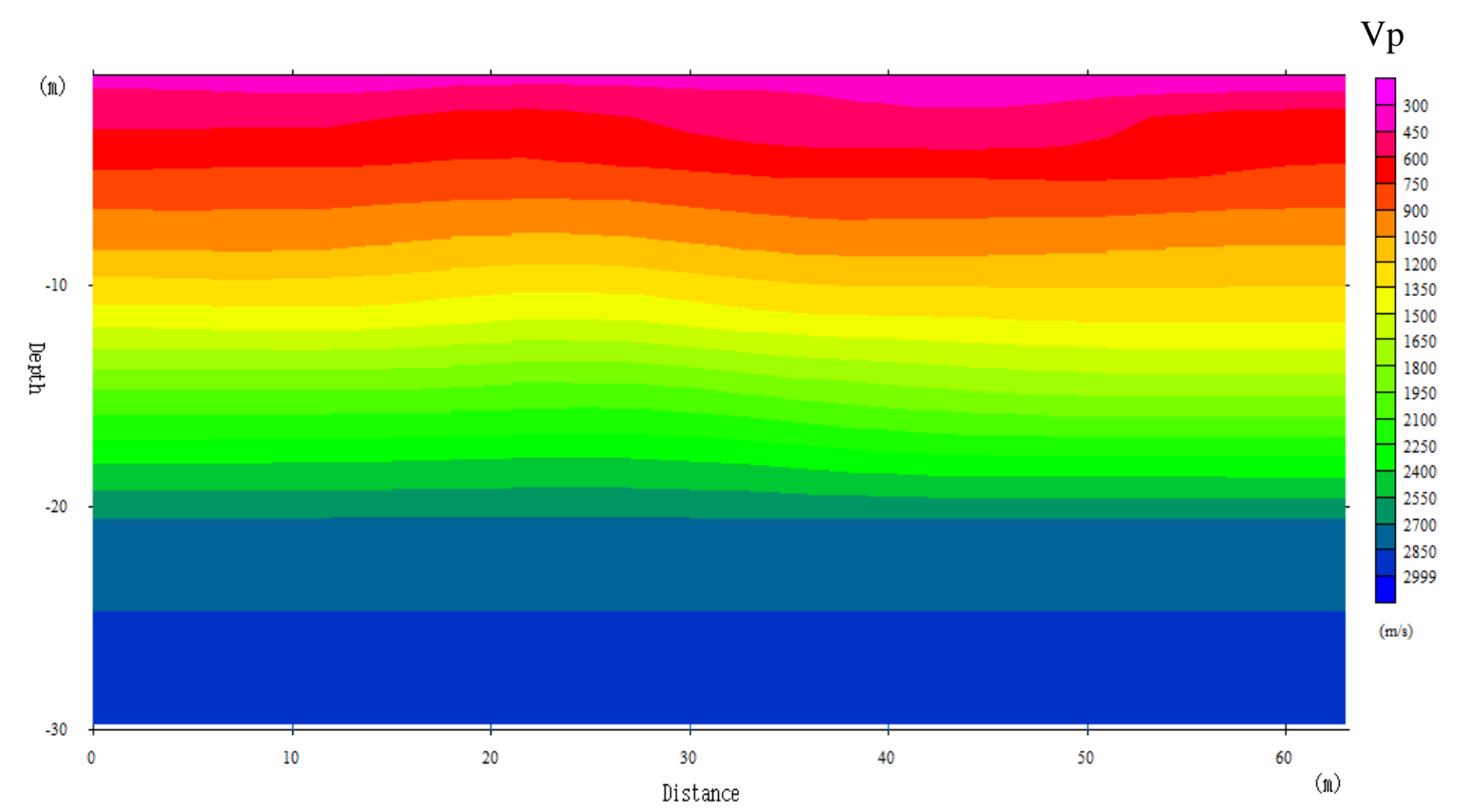

b: Layered model

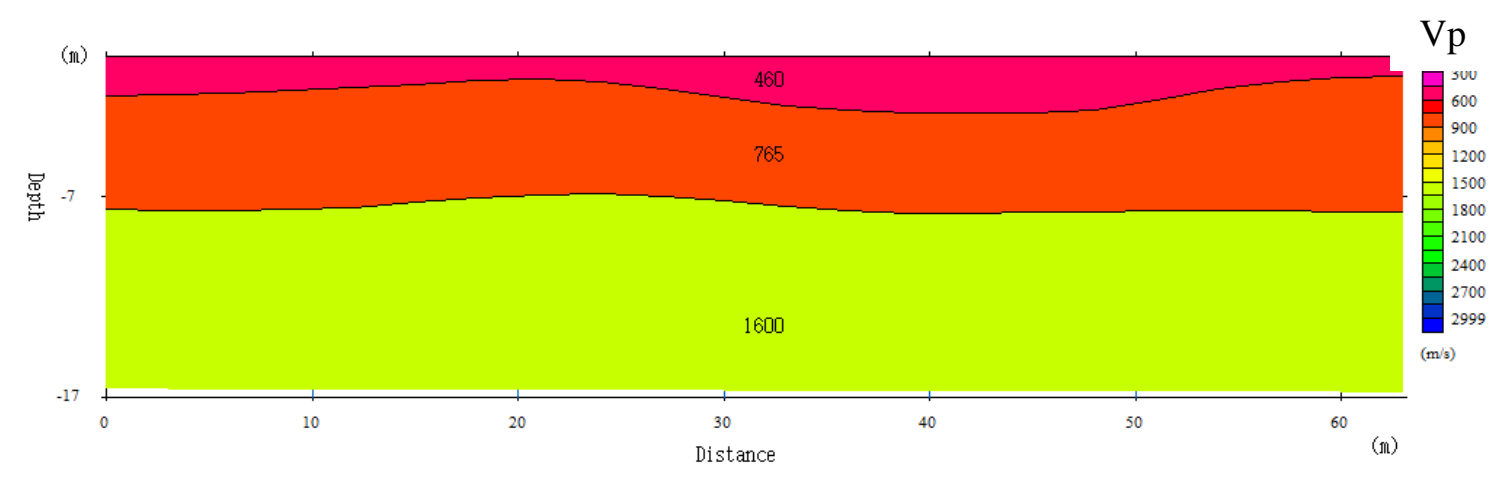

الثكل 3: يمثل a مقطع زلزالي تصويري للخط الرابع.

b : مقطع زلزالي طبقي للخط الرابع. 

استخدام طريقة المسح الزلزالي الانكساري التصويري وتقنية التحليل متعدد القنوات للموجات.

\section{a: Seismic Refraction}

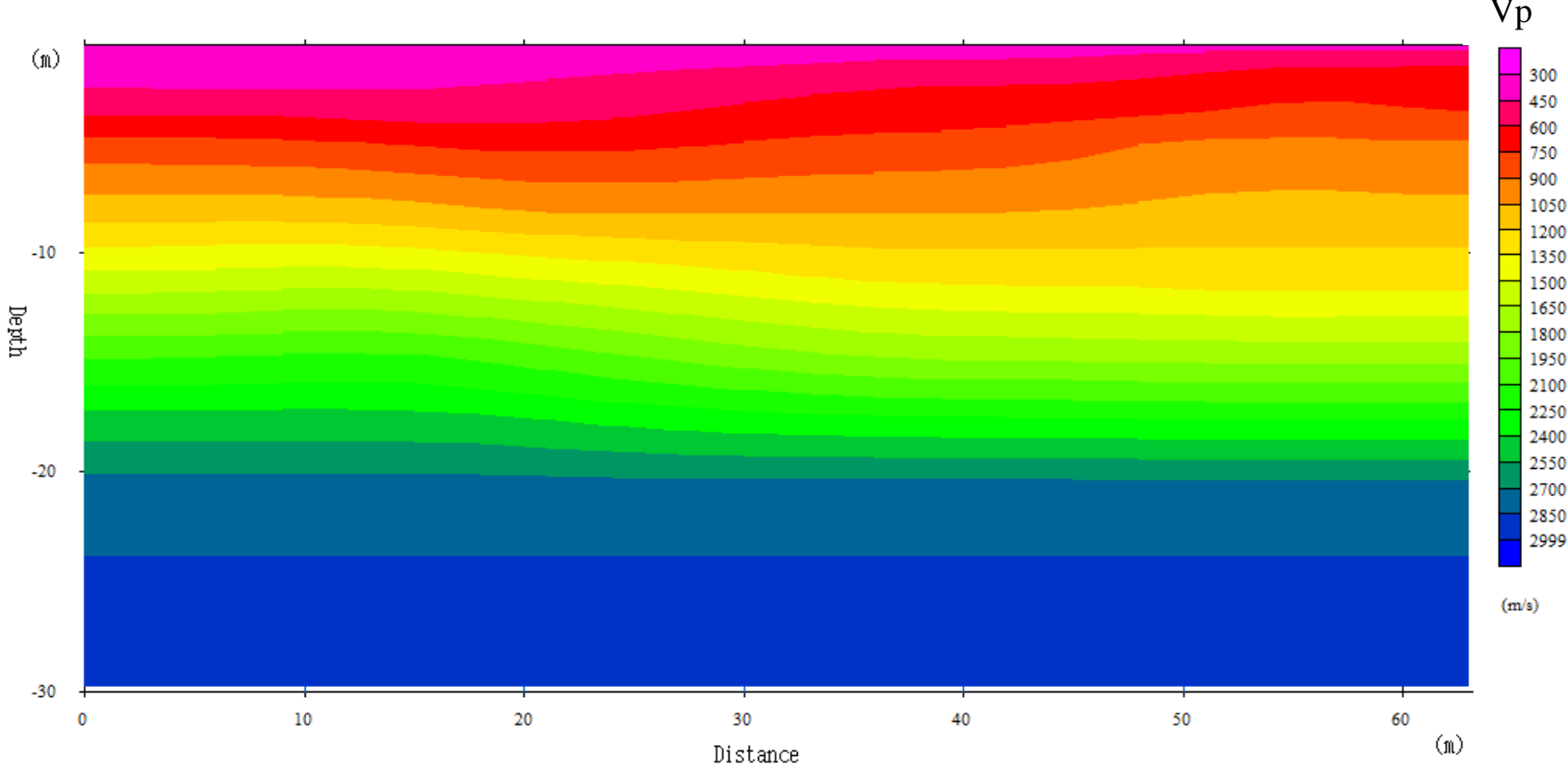

b: Layered model

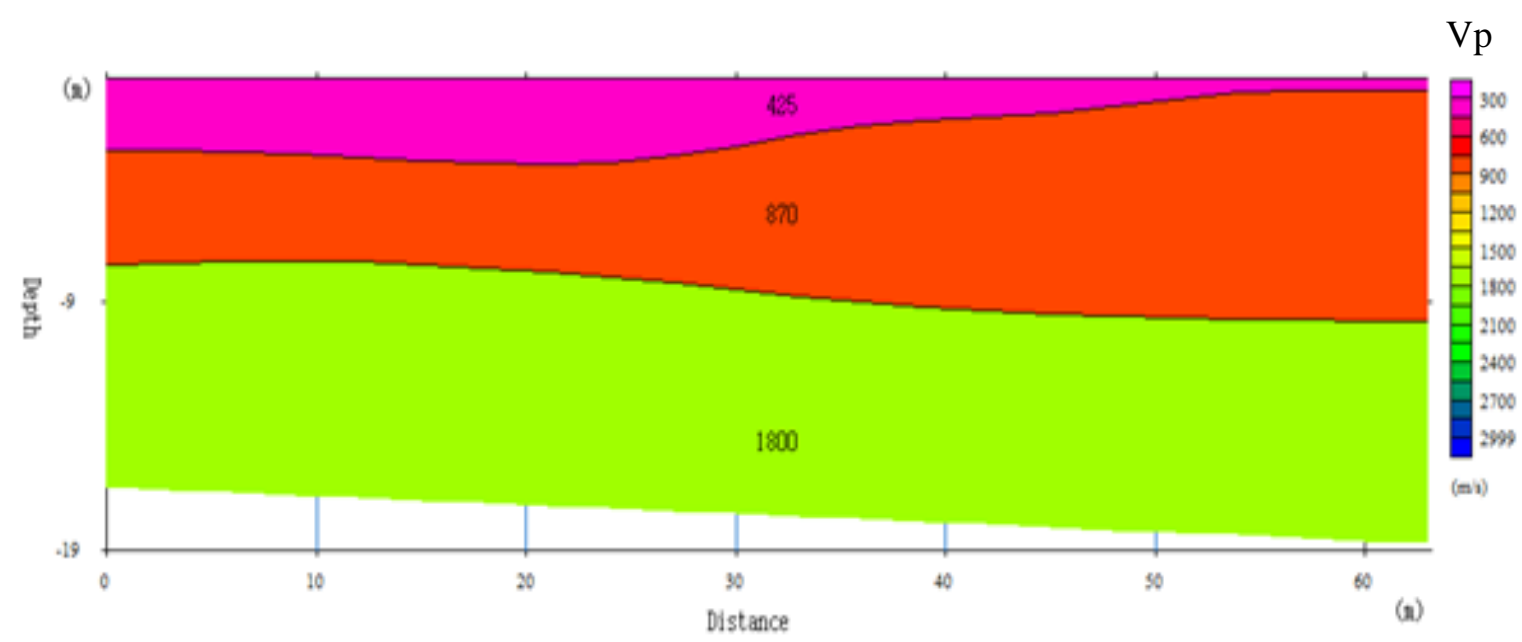

الثكل 4: يمنل a مقطع زلزالي تصويري للخط السابع.

b: مقطع زلزالي طبقي للخط السابع. 


\section{MASW المعالجة وتفسير البيانات بتقنية}

تتم عملية المعالجة عن طريق تحليل بعض خصائص التشتت، منل سرعة طور موجات رايلي كدالة

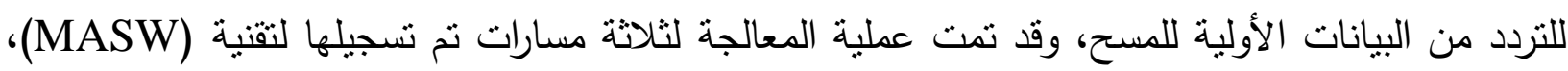

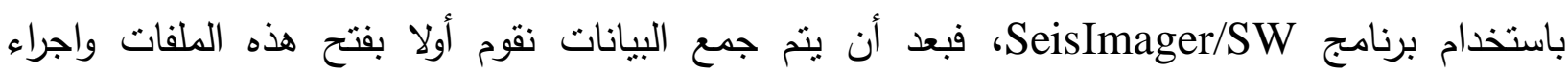

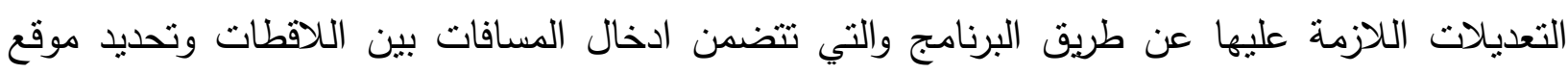
نقطة المصدر، وتأتي الخطوة الثانية وهي حساب التتنت وتتثكيل منحنيات التتتت عن طرق تحويرية (f-k)

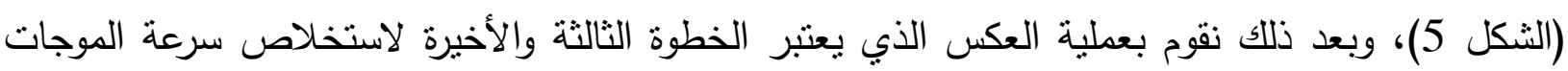

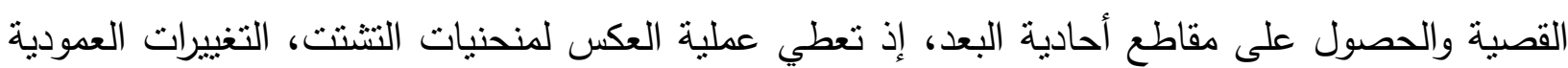
في سرعات الموجات القصية (Vs) مع العمق تحت منطقة التحري.

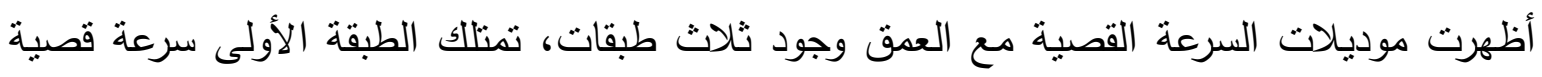

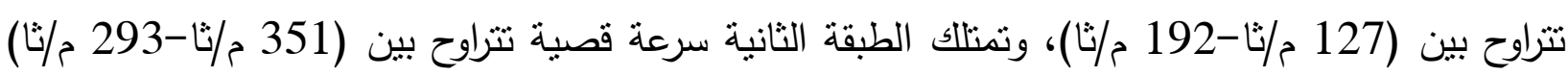

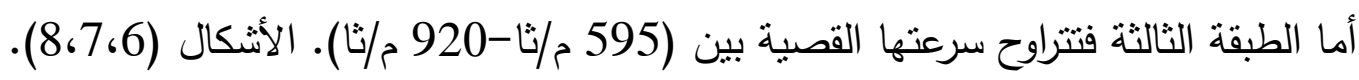

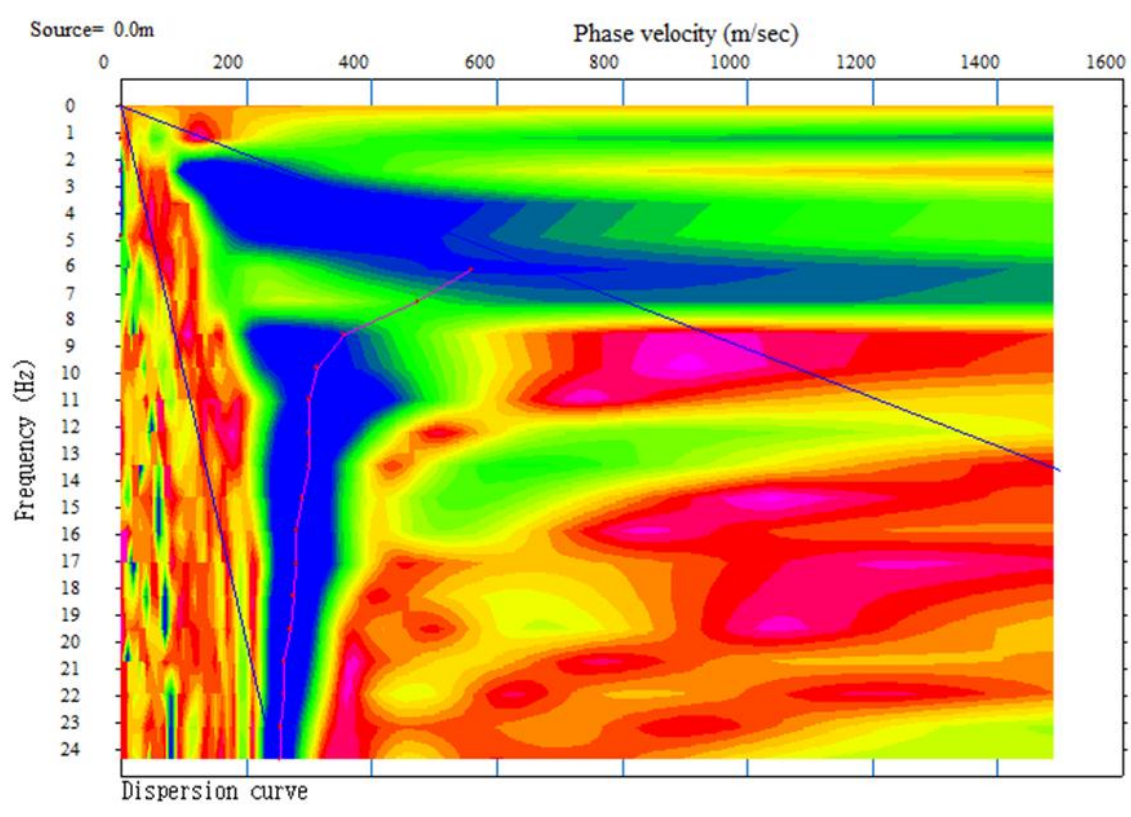

الثكل 5: يظهر منحني التشتت (Dispersion Curve). 

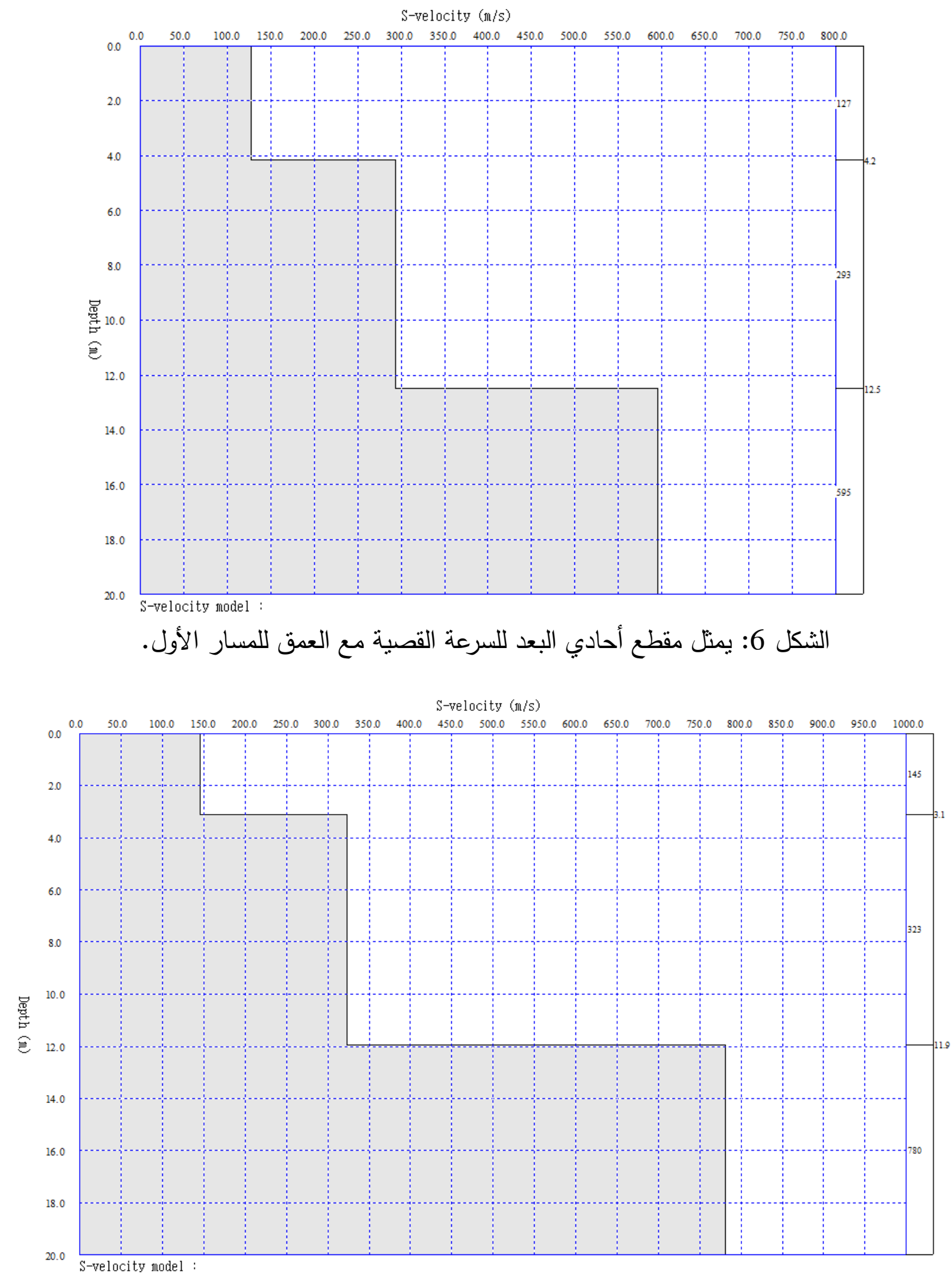

الشكل 7: يمنل مقطع أحادي البعد للسرعة القصية مع العمق للمسار الثاني. 


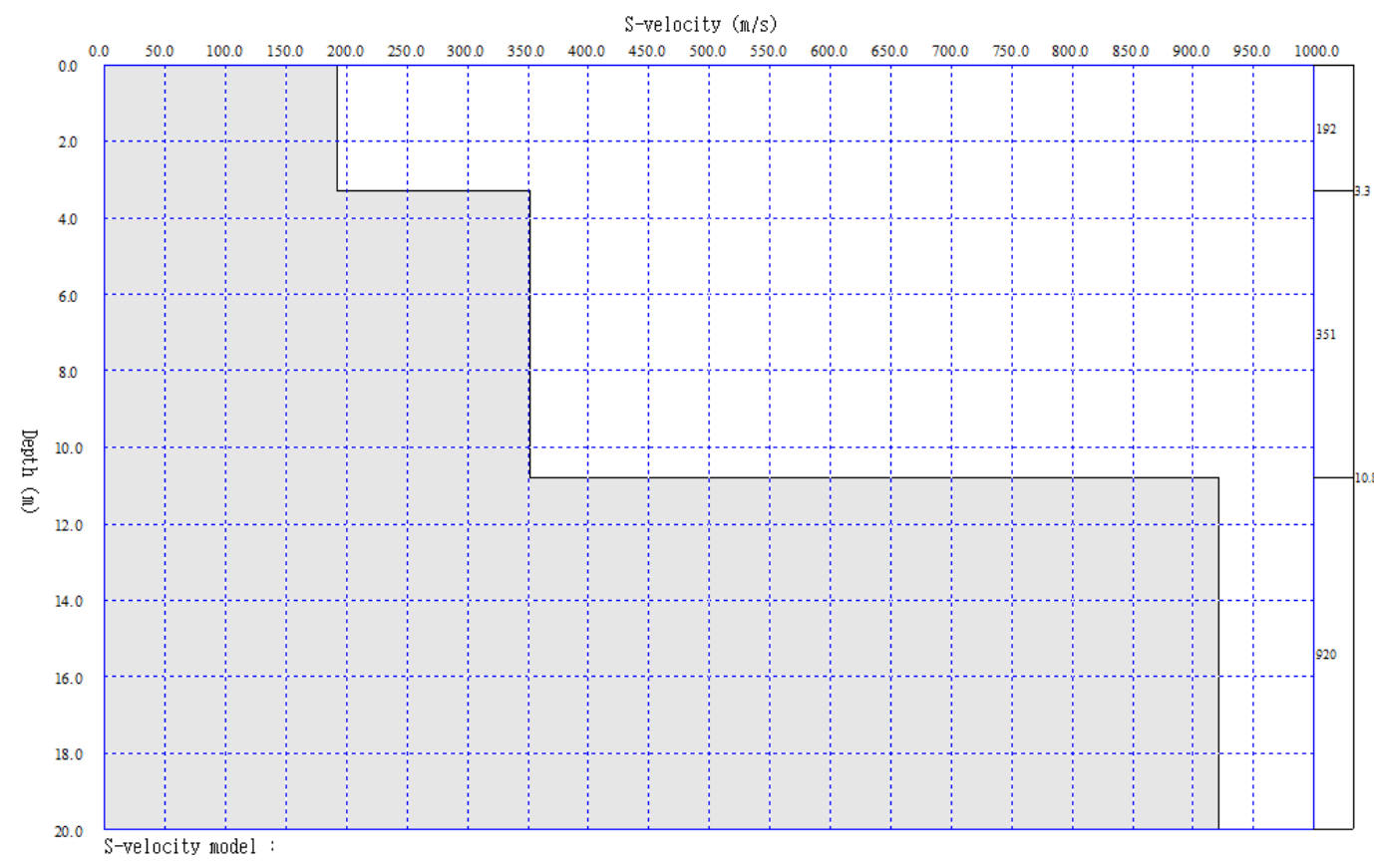

الثكل 8 :يمنل مقطع أحادي البعد للسرعة القصية مع العمق للمسار الثالث.

\section{حساب قيم الكثافة}

تم حساب قيمة الكثافة (م) للطبقات بطريقة المخروط الرملي (sand cone)، وتتلخص هذه الطربقة بعمل حفرة دائرية الثكل بقطر حلقة الجهاز، وبمقدار (20 سم)، وتم وزن كمية التربة المستخرجة منها بميزان الكتروني، ثم ثم ملء الحفرة برمل معلوم الكثافة والوزن، ومن خلال معادلات رياضية بسيطة تُحسَب الكثافة الحقلية لكل طبقة.

\section{التقبيم الجيوتكنيكي}

ان عملية التقييم الجيوتكنيكي للمواقع لها أهمية كبيرة جدا في الأعمال الهندسية المدنية، لذلك تم حساب الخصائص الجيوتكنيكية بالاعتماد على قيم سرعات الموجات الزلزالية (VP) و (VS) وقيم الكثافة

المقاسة حقليا كما موضح بالجداول (1) و (2).

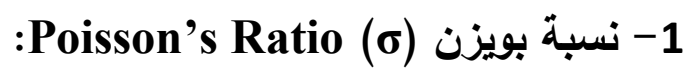
تُعَد هذه النسبة عاملا مهما في الأعمال الهندسية، اذ يتم حسابها أكثر من غيرها، وقد تراوحت قيم هذه النسبة بين (0.39 - 0.41) للطبقة الأولى، وبين (0.38 - 0.40) للطبقة الثانية، أما الطبقة الثالثة 
فتتراوح بين (0.32 - 0.35)، ويدل انخفاض قيمة هذه النسبة على زيادة الصلابة، إذ ان العلاقة بين

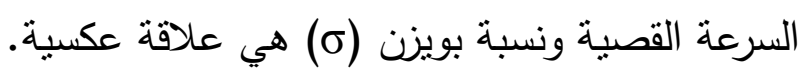

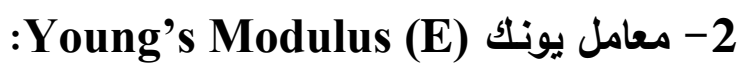

يعد من المعاملات المهمة؛ وذللك بسبب علاقته مع المعاملات الأخرى، فتزداد قيمة هذا المعامل

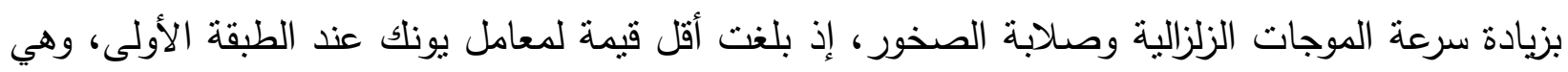

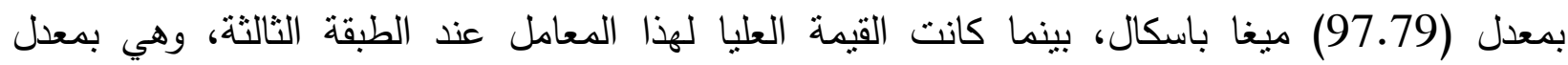
(2897.67) ميغا باسكال. إذ إن العلاقة بين السرعة القصية ومعامل يونك هي علاقة طئة طردية.

3- المعامل الحجمي Bulk Modulus (K)

تم حساب هذا المعامل من خلال علاقته مع معامل يونك ونسبة بويزن، وقد بلغت قيمة معدل هذا المعامل للطبقة الأولى (177) ميغا باسكال، وللطبقة الثانية (754.38) ميغا باسكال، أما الطبقة الثالثة فبلغت (2896.9) ميغا باسكال.

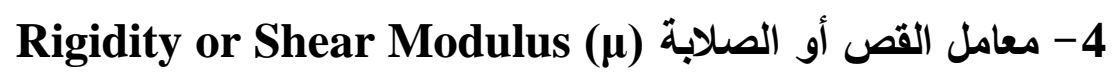
يعد من المعاملات المهمة من الناحية الهندسية، إذ تزداد قيمة هذا المعامل بزيادة العمق وزيادة سرعة

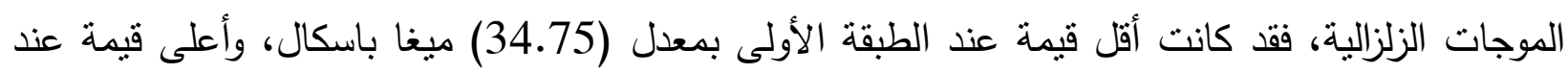
الطبقة الثالثة بمعدل (1087.76) ميغا باسكال

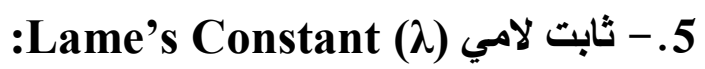

يمثل هذا المعامل مقياسا لمقاومة الوسط المتجانس، إذ بلغت قيمة معدل هذا المعامل للطبقة الأولى

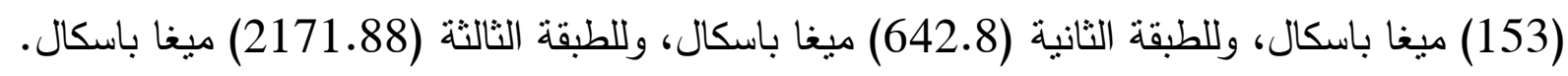

:Material Index (V) معامل المادة

يعد من المعاملات الجيوتكنيكية المهمة، ويمثل درجة كفاءة المواد، إذ تستخدم قيمة هذا المعامل لتحديد

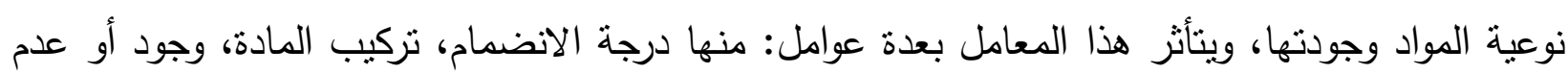

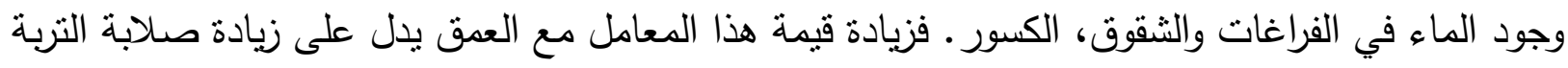

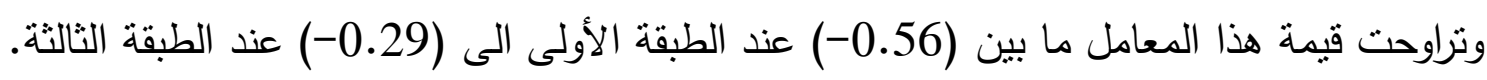

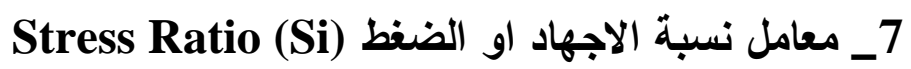

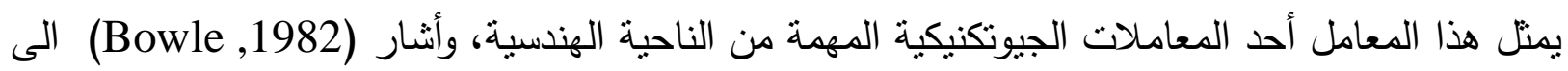

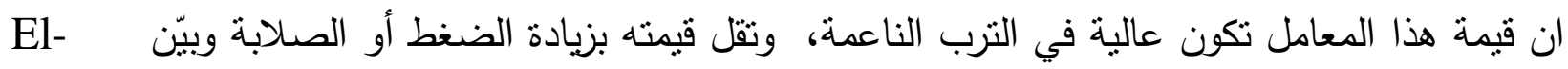
Abd Rahman(1991)

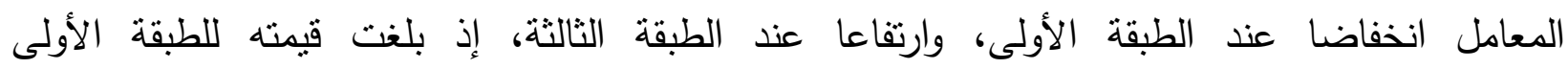

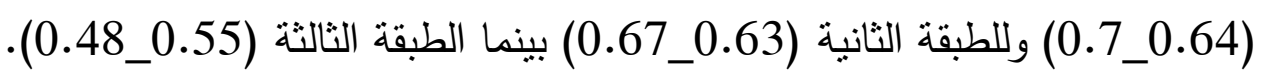




\section{Conclusions الاستنتاجات}

1- أظهرت طريقة المسح الزلزالي الانكساري التصويري (SRT) نتائج جيدة جدا في تحديد وضعية الطبقات تحت السطحية، وتم الحصول على مقاطع تصويرية زلزالية

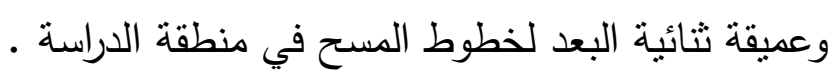

2- أظهرت تقنية التحليل متعدد القنوات للموجات السطحية Multi-channel Analysis of (MASW)

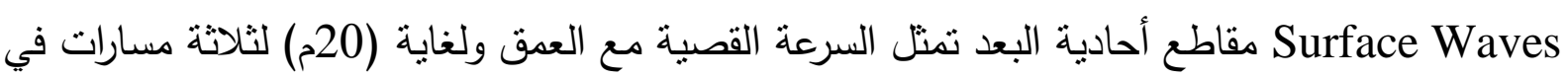

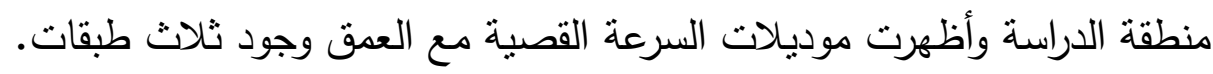

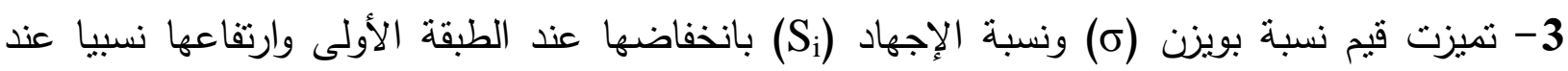

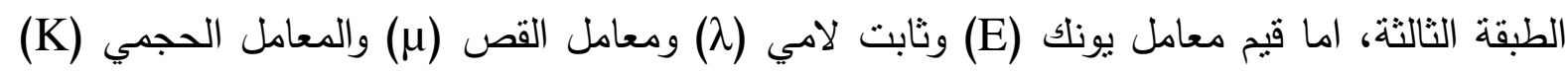

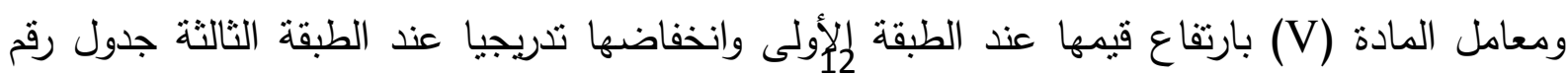

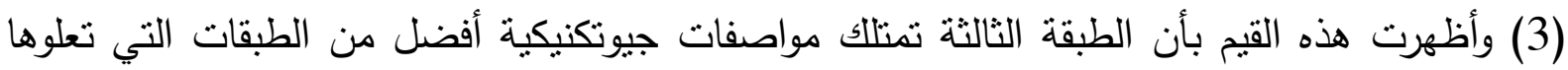
وبذللك تكون مناسبة لإقامة المشروع الهندسي علئ الهيها. الجدول 1: المعادلات المستخدمة في حساب معاملات المرونة.

\begin{tabular}{|c|c|c|c|}
\hline $\begin{array}{l}\text { Elastic } \\
\text { Module }\end{array}$ & Used Formula & & Reference \\
\hline $\begin{array}{l}\text { Poisson's } \\
\text { Ratio }(\delta)\end{array}$ & $\sigma=\frac{1}{2}\left[1-\frac{1}{\left(V_{p} / V_{s}\right)^{2}-1}\right] \sigma=\frac{1}{2}$ & $1-\frac{1}{\left(\frac{V s}{V p}\right)^{2}-1}$ & $\begin{array}{l}\text { Adams (1951), } \\
\text { Salem (1990) }\end{array}$ \\
\hline $\begin{array}{l}\text { Young's } \\
\text { Modulus (E) }\end{array}$ & $\begin{array}{r}E=\rho\left[\frac{3 V p^{2}-4 V s^{2}}{\left(\frac{V p}{V s}\right)^{2}-1}\right. \\
\mathrm{E}=\rho\left[\frac{3 \mathrm{Vp}^{2}-4 \mathrm{Vs}^{2}}{\left(\frac{\mathrm{Vs}}{\mathrm{V}}\right)^{2}-1}\right]\end{array}$ & & Adams (1951) \\
\hline $\begin{array}{l}\text { Bulk } \\
\text { modulus (K) }\end{array}$ & $K=\frac{E}{3(1-2 \sigma)}$ & & $\begin{array}{l}\text { K. Knödel,et } \\
\text { al., (2007) }\end{array}$ \\
\hline $\begin{array}{l}\text { Shear } \\
\text { Modulus }(\mu)\end{array}$ & $\mu=\left[\frac{E}{2(1+\sigma)}\right]$ & & $\begin{array}{l}\text { King (1966), } \\
\text { Toksoz et al., } \\
(1976)\end{array}$ \\
\hline $\begin{array}{l}\text { Lame's } \\
\text { Constants }(\lambda)\end{array}$ & $\lambda=\frac{\sigma E}{(1+\sigma)(1-2 \sigma)}$ & & $\begin{array}{l}\text { King (1966), } \\
\text { Toksoz et al., } \\
\text { (1976) }\end{array}$ \\
\hline
\end{tabular}




\begin{tabular}{|c|c|c|}
\hline Index Material (V) & $V=\frac{3-\left(V_{p} / V_{s}\right)^{2}}{\left(V_{p} / V_{s}\right)^{2}-1}$ & $\begin{array}{c}\text { Abd El-Rahman et al., } \\
\text { (1994) }\end{array}$ \\
\hline Stress Ratio $\left(\mathrm{S}_{\mathrm{i}}\right)$ & ()$^{2}$ & Abd El-Rahman, (1991) \\
\hline
\end{tabular}

الجدول 3: يوضح معاملات المرونة والمعاملات الجيوتكنيكية التي تم حسابها.

\begin{tabular}{|c|c|c|c|c|c|c|c|c|c|}
\hline $\mathbf{V}_{\mathbf{p}} \mathbf{m} / \mathbf{s}$ & $\begin{array}{l}\text { Vs } \\
\mathrm{m} / \mathrm{s}\end{array}$ & $\rho \mathrm{gm} / \mathrm{cc}$ & $\sigma$ & $\begin{array}{c}\mathbf{E} \\
(\mathbf{M p a})\end{array}$ & $\begin{array}{c}\mathbf{K} \\
\text { (Mpa) }\end{array}$ & $\begin{array}{c}\mu \\
(\mathbf{M p a})\end{array}$ & $\lambda$ (Mpa) & V & $\mathbf{S i}$ \\
\hline \multicolumn{10}{|c|}{ الطبقة الاولى } \\
\hline 300 & 127 & 1.27 & 0.39 & 56.98 & 86.99 & 20.48 & 73.33 & -0.56 & 0.64 \\
\hline 500 & 192 & 1.33 & 0.41 & 138.6 & 267.13 & 49 & 234.44 & -0.65 & 0.70 \\
\hline \multicolumn{10}{|c|}{ الطبقة الثانية } \\
\hline 680 & 293 & 1.56 & 0.38 & 371.24 & 542.78 & 133.92 & 453.49 & -0.54 & 0.63 \\
\hline 870 & 351 & 1.63 & 0.40 & 563.41 & 965.99 & 200.82 & 832.11 & -0.61 & 0.67 \\
\hline \multicolumn{10}{|c|}{ الطبقة الثالثة } \\
\hline 1250 & 595 & 1.77 & 0.35 & 1696.3 & 1930 & 626.62 & 1512.38 & -0.41 & 0.55 \\
\hline 1800 & 920 & 1.83 & 0.32 & 4099 & 3863.98 & 1548.91 & 2831.38 & -0.29 & 0.48 \\
\hline
\end{tabular}

\section{المصادر العربية}

الخفاجي، عمار جاسم محمد، 2015. المسح الزلزالي البئري والجيوتكنيكي لنربة موقع فندق الخيام محافظة

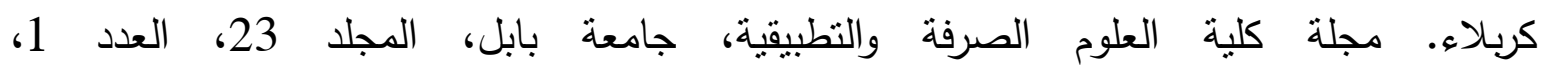

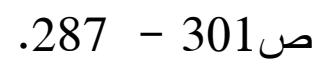
الهيتي، أحمد جدوع رضا، 2014. مسح زلزالي انكساري لموقع مشروع المستثفى التعليمي في جامعة الموصل. رسالة ماجستير، كلية العلوم، جامعة الموصل، 125 صفحة.

\section{المصادر الاجنبية}

Abd El-Rahman, M., 1991. The Potential of Absorption Coefficient and Seismic Quality Factor in Delineating Less Sound Foundation Materials in Jabal Shib Az Sahara Area, Northwest of Sanaa, Yemen Arab Republic, Egypt. M.E.R.C. Earth Sciences, Ain Shams University, Egypt, Vol. 5, pp. 181 - 187. 
Abdel-Rahman, M., Helal, A.N.M.A., Mohamed, H.C. and Al-Malqi, I., 1994. Exploration Seismic for Site evaluation of the new city of El-Minya, EgyptE.G.S. proc. of the 12th Ann. Meet. pp. 59 - 74.

Adams, L.H.,1951. Elastic Properties of Materials of the Earth's Crust. Internal Construction of the Earth (edited by Gutenberg), Dover Publications, Inc., New York.

Azwin, I.N., Saad, R. and Nor Diana, M., 2013 . Applying the Seismic Refraction Tomography for Site Characterization, APCBEE Procedia 5, January 19 - 20, Dubai, UAE, pp. 227 - 231.

Bellen, R., Dunnington, H., Wetzel, R. and Morton, D., 1959. Lexique Statigraphique International, Vol.3, Iraq, Asia, 10a, 333 p.

Bowles, J.E., 1982. Foundation Analysis and Design, 2nd Ed. McGraw-Hill International Book Company, London, $587 \mathrm{p}$.

Hamzah, U. and Samsudin, A., 2006 . 2D Seismic Refraction Tomography Survey on Met sediment at a Proposed Development Site in Dengkil, Selangor, Geological Society of Malaysia Bulletin, 52, pp. 1 - 6.

Jassim S. Z. And Goff J.C. 2006 . Geology of Iraq. 1st Edition Dolin, Prague and Moravian Museum, Brno, Czech Republic, 408 p.

King, T.V.V., 1966 . Mapping Organic Contamination by Detection of Clay-Organic Processes, Proceeding Association of Ground Water Scientists and Engineers (AGWSE) / National Water Well Association (NWWA)/API.

Khorshid, S.Z., Al-Awsi, M. and AL-Banna, A., 2014. Geotechnical Evaluation to the Soil of Tikrit University Using Seismic Refraction Method, Diyala Journal Pure Sciences, 10, 17 p.

Knödel, K., Lang, G. and Voigt, H.J., 2007 . Environmental Geology, Handbook of Field Methods and Case Studies, Hannover Federal Institute for Geosciences and Natural Resources, Springer Books, 1357 p.

Park, C.B., Miller, R.D. and Xia, J., 1999 . Multichannel analysis of surface waves, Geophysics, Vol. 64, No.3, pp. 800 - 808.

Park, C.B. Miller, R.D. Xia, J. Ivanov, J., 2007 . Multichannel Analysis of Surface Waves (MASW)-Active and Passive Methods, The Leading Edg, pp. 60 - 64.

Salem, H.S., 1990 . A Theoretical and Practical Study of Petrophysical, Electric and Elastic Parameters of Sediments, Ph.D. Thesis, Kiel University, F. R. Germany, Publish by University Microfilms International (UMI), MI, USA, $200 \mathrm{p}$.

Sissakian, V.K., 1992. The Geology of Kirkuk Quadrangle, sheet NI - 38 - 2, scale 1: 250 000. GEOSURV, Baghdad, Iraq .

Shaker, A. M., 2012. Geophysical and Geotechnical Study of a Proposed Tunnel Site at Al-Najaf City, Southern Iraq. Unpublished Ph.D. thesis, Collage of Science, Baghdad University, $108 \mathrm{p}$.

Toksoz, M.N., Cheng, C.H. and Timur, A., 1976. Velocities of Seismic Waves - Porous Rocks, Geophysics, Vol. 41, pp. 621 - 645. 